\title{
Artigos
}

Daniela Finco'

Gabriella Seveso2

\section{Estereótipos de gênero e sexismo linguístico presentes nos livros no contexto educativo para crianças}

Resumo: Na Itália, desde os anos setenta, houve um debate significativo dos estudos sobre o sexismo linguístico que contribuíram para pensar a problematização da presença dos estereótipos de gênero nos livros destinados para crianças. Este artigo apresenta uma reconstrução histórica do debate desenvolvido na Itália, nos últimos quarenta anos. O debate mostrou a importância de problematizar os padrões de identidade e comportamento transmitidos através da leitura em contextos educativos e na escola. Este contexto resultou na elaboração do Projeto Polite, que convida editoras a serem respeitosas com as diferenças de gênero, tanto no texto e quanto nas imagens. Apresenta importantes pesquisas sobre a problemática da presença de mensagens estereotipadas de gênero presentes nos livros paras as crianças e as mudanças ocorridas ao longo deste processo.

Palavras-chave: Gênero. Educação da Infância. Literatura Infantil, sexismo linguístico.

\section{Gender stereotypes and linguistic sexism present in books in educational context for children}

Abstract: In Italy, since the 1970s, there has been a significant debate on the studies on linguistic sexism that have contributed to the problematization of the presence of gender stereotypes in children's literature. This article presents a historical reconstruction of the debate developed in Italy in the last forty years. The debate showed the importance of problematizing the patterns of identity and behavior transmitted through reading in educational contexts for children. This context also led to the drafting of the Polite Project, which invites editors to be respectful with gender differences, both text and images. It presents important research on the problem of the presence of stereotyped messages of gender present in books for children and the changes that have occurred throughout this process.

Keywords: Gender. Childhood Education. Children's Literature, linguistic sexism.

\footnotetext{
1 Doutora em Educação pela Universidade de São Paulo - USP. Professora no Departamento de Educação da Escola de Filosofia, Letras e Ciências Humanas, Universidade Federal de São Paulo - UNIFESP. E-mail: dfinco@unifesp.br

2 Professora no Departamento de Ciências Humanas para a formação, Università degli Studi di Milano-Bicocca. E-mail: gabriella.seveso@unimib.it
} 
ste artigo aborda a questão dos estereótipos de gênero e do sexismo linguístico presentes nos livros escolares e livros de literatura infantil destinados às crianças. Alerta para a questão da linguagem, que contribui de maneira significativa para a construção do caráter socialmente construído das diferenças sexuais entre meninas e meninos, mulheres e homens. As discussões apresentadas neste artigo foram geradas no contexto da pesquisa de Pós-doc realizada na Universidade de Milano Bicocca, na Itália ${ }^{3}$. A discussão o sexismo linguístico está ligada a uma educação para emancipação das relações de gênero que deveria ser de relevância na formação inicial e em serviço de todos os/as profissionais da educação, pelo seu potencial de transformação cultural e social, conforme apontam inúmeras pesquisas italianas e brasileiras (Faria, 2006; Ulivieri, 2007; Biemmi, 2010a, 2010b; Leonelli, 2011; Seveso, 2015; 2016; Finco e Silva, 2015; Finco, Souza e Cruz, 2017).

Estudos Italianos e brasileiros (Botton e Strey, 2012; Argüello, 2005; Seveso, 2015) apontam chamam a atenção para a "pedagogia invisível" dos livros infantis. Uma Pedagogia invisível "que se refere à possibilidade de transmissão de valores e de formas aceitáveis de comportamentos sociais através da literatura infantil, a fim de que as crianças sigam e correspondam o que está sendo ensinado" (Botton e Strey, 2012, p. 25). A literatura para a infância é de fato percebida como uma tipologia de importância secundária, e isto causa uma grave ignorância da influência notável que, ao contrário, ela pode desenvolver na vida de meninos e meninas. (Seveso, 2016).

A literatura infantil desempenhou ao longo da história, e ainda desempenha, uma função muito importante do verdadeiro patrimônio simbólico das metáforas da infância, das representações de infância e da relação entre mundo adulto e mundo infantil. Em particular, os livros infantis são ferramentas muito poderosas para a transmissão de modelos tradicionais ou diversificados de crianças e meninas. (Beseghi, 2016).

Ler livros que apresentam diferentes formas de pertencimento pode ser muito útil para expandir as diferentes possibilidades relacionadas ao gênero, possibilitando a reflexão sobre estereótipos de gênero. Alguns estudos confirmam que tomar consciência de informações estereotipadas pode promover uma maior flexibilidade e respeito à diversidade de gênero (De Caroli e Sagone 2010). Em particular, ler livros com papéis de gênero não estereotipados pode reduzir o pensamento estereotipado e a ideia de que

3 Pesquisa Pedagogia das diferenças de gênero para a educação da primeira infância: um estudo sobre as literaturas infantis adotadas nas creches e pré-escolas italianas, realizada entre 2016 e 2017 na Università degli Studi di Milano-Bicocca, financiada pela FAPESP. 
algumas atividades, comportamentos são mais adequados para meninas e meninos (Romatowski e Trepanier-Street, 1999).

$\mathrm{Na}$ Itália, desde os anos setenta, houve um debate significativo sobre o sexismo linguístico que contribuíram para pensar a problematização da presença dos estereótipos de gênero nos livros destinados às crianças. Desse modo, este artigo apresenta e discute o resultado de pesquisas que apontam como as crianças aprendem o sexismo ao se defrontar com as hierarquias de gênero, impressas nos livros destinadas às crianças, nas quais os papéis tradicionais feminino e masculino estão determinados, com uma linguagem e mensagem sexista. Apresenta uma reconstrução histórica do debate desenvolvido na Itália, nos últimos quarenta anos. O debate mostra a importância de problematizar os padrões de identidade e comportamento de gênero transmitidos através da leitura em contextos educativos. Apresenta importantes pesquisas sobre a problemática da presença de mensagens estereotipadas presentes nos livros paras as crianças e destaca as mudanças ocorridas ao longo deste processo.

\section{Sexismo linguístico e estereótipos nos livros para crianças}

A pesquisa sobre o sexismo linguístico e sobre os estereótipos nos livros escolares começou na Itália nas décadas de 1970 e 1980 com uma reflexão proposta por Elena Gianini Belotti e continuou com uma interessante investigação conduzida por Rossana Pace (1986a, 1986b) que contribuiu para o processo de renovação de conteúdos, métodos e materiais didáticos italianos. O estudo de Pace buscou refletir e oferecer subsídios para autoras/es e editoras/es, para publicação de textos sensíveis questões de gênero e a questão das diferenças, dos direitos e do respeito pelo outro. A investigação não tinha intenção ou atitude de censura, mas tinha um objetivo de reflexão e melhoria, assim como refletir sobre o papel das instituições de educação frente a estas questões.

De acordo com a pesquisa de Rossana Pace (1986a, 1986b) a tarefa da instituição escolar deveria ser oferecer uma imagem realista da sociedade e do mundo em que vivemos, evitando propor um passado estancado e idealizado. Por esse motivo, ela argumentou que os conteúdos dos livros deveriam incorporar uma variedade de situações, exemplos, profissões, papéis familiares e sociais que podem refletir a realidade. "A escola não deve apenas refletir o que está acontecendo na sociedade, mas também antecipar as mais avançadas propostas culturais e ideológicas na própria sociedade " (Pace, 1986b, p 11). Para a autora a escola deveria ser uma força motriz para mudanças positivas e não uma instituição irreal e antiga que não transmite confiança. Ao acreditar no potencial da escola, não seria aceitável continuar usar livros educativos que propõem uma realidade imóvel, com estereótipos de gênero que não correspondem mais à realidade.

Rossana Pace (1986b), questionou também as possíveis explicações sobre o atraso dos textos escolares daquela época na Itália. $\mathrm{Na}$ opinião da autora, a possível causa foi a forte desinvestimento e desengajamento político em relação à escola: a escola foi vista como uma instituição fraca e menos intensa do que outras agências educacionais e de formação destinadas a crianças e jovens; na verdade, embora 
houvesse um interesse comum no desenvolvimento econômico, social e cultural do país, a escola era considerada inútil e inapropriada para assumir o papel de fator de mudança; por esse motivo, os materiais escolares não receberam a devida atenção e não foram avaliados em relação aos temas sociais.

Dada a homogeneidade encontrada nos resultados da pesquisa, Rossana Pace acreditava que dados semelhantes poderiam ter sido obtidos a partir de uma amostra maior, mas as conclusões de seu estudo são consideradas representativas da realidade editorial da década de 1980 na Itália. Sobre o aspecto representatividade de gênero, por exemplo, a autora relatou os principais dados quantitativos: $78 \%$ das crianças em textos eram do sexo masculino (242) e $28 \%$ eram do sexo feminino (98). No que diz respeito aos adultos, as percentagens foram de 65\% para homens (392) e 35\% para mulheres (215).

O sexo masculino, portanto, dominou do ponto de vista quantitativo nos livros; algumas personagens femininas adultas ainda estavam presentes como, mas poucas meninas pequenas. Além disso, os numerosos papéis estereotipados foram identificados relacionados à família: o pai era o único membro da família que realizava um trabalho remunerado e, portanto, era ligado ao âmbito público. Pelo contrário, a mãe sempre representada na dimensão interna da casa e da família, no âmbito privado, e mesmo poucas vezes quando ela tinha um emprego, não se tratava de um trabalho de responsabilidade, mas sim desqualificado e mal pago.

Tanto os textos quanto as imagens em muitos livros eram distantes do tempo presente, derivado possivelmente da reutilização de volumes antigos sem mudanças e atualizações. Em muitos aspectos, os volumes pareciam reproduzir uma realidade inalterada a partir da década de 1960: marcada por fenômenos tradicionais desta época na sociedade italiana, como o ciclo das estações a realidade agrícola e a vida no campo que foram apresentadas como inalteradas, sem nenhuma atualização das mudanças sociais. Neste contexto, ficou evidente que não havia espaço para a mulher com um emprego remunerado: várias páginas de livros apresentavam apenas trabalhadores masculinos, e uma mulher que estava a espera para se casar, ou uma mãe dona de casa que se ocupava do trabalho doméstico. Certamente, naquele tempo ainda havia muitas donas de casa, e os/as autores/as tiveram a intenção de não minar sua contribuição e seu papel. Porém, o problema real analisado por Rossana era que nos livros analisados não havia mulheres em outros papéis e representações que poderia contrabalançar-los.

A família representada nos livros era fortemente tradicional, com a mãe dona de casa e pai trabalhador e provedor. Sobre o pai se falava somente em função de seu emprego. As únicas expressões emocionais que ele apresentava estavam relacionadas à sua posição de trabalho, em oposição à mãe que muitas vezes chorava. Rossana Pace enfatiza também que mesmo em livros onde as editoras estavam envolvidas em uma renovação gráfica, usando fotografias a cores em vez de desenhos, as imagens pareciam reproduzir ambientes e situações semelhantes ao passado: o pai sentado na poltrona na sala de estar lendo o jornal, e a mãe na cozinha preparando o jantar para todos. Os exemplos que foram encontrados na pesquisa de Rossana Pace revelaram livros que não mostravam outras imagens para contrabalancear essa representação, que reforçavam o estereótipo tradicional de mulher e, acima de tudo, não sugeririam às crianças e meninas uma evolução do papel feminino. 
A autora também analisou os estereótipos presentes nos problemas dos livros de matemática, pois esses são textos aparentemente "neutros" e relacionados a uma disciplina aparentemente sem relação com as representações sociais: como se a atenção do menino e da menina neste caso estivessem muito focada na busca da solução do problema e, portanto, não perceberia quaisquer mensagens de gênero ou relacionadas aos protagonistas que estão em consideração. A autora revelou alguns exemplos: em uma página para aprender a ler os gráficos, apenas a população masculina ativa era representada, enquanto poderia ser uma boa oportunidade para considerar os dados sobre a população total ocupada.

As meninas também eram representadas como frágeis: por exemplo, na rua lugar que representava vários perigos, havia apenas homens que viviam suas primeiras experiências fora do lar. Em alguns casos, as discrepâncias podem ser encontradas entre a mensagem de texto e a mensagem da ilustração, como no caso de um menino que narrava em primeira pessoa a forma como ajudava a sua irmã a fazer as tarefas domésticas, mesmo que esta não fosse uma atividade que lhe agradava. A imagem era fortemente contrastante: enquanto a irmã com a vassoura na mão cuidava da limpeza, o menino estava sentado em um banco falava. Estes dados mostraram como os textos escolares da década de 1980 apresentavam uma realidade social e familiar pouco realista. Além disso, revelavam a centralidade nas imagens dos homens, não havia um equilíbrio nem a intenção de dar visibilidade às imagem das mulheres.

Esse tipo de produção, portanto, se demonstrou atrasada e pouco emancipada, em relação à realidade social, o que também podia ser observado nos livros infantis não escolares. Nos livros de narrativa e ficção destinados a meninas e meninas, a presença de personagens femininas, na década de 1980 aumentaram e os estereótipos de gênero foram menos marcados e presentes, revelando figuras de meninas mais ativas e capazes. Porém, nos textos estudados por Rossana Pace (1986b), os protagonistas continuaram a estar na esmagadora maioria dos homens e figuras femininas intimamente relacionadas ao papel tradicional. Os exemplos positivos eram poucos: mulheres e homens em um texto dedicado ao esporte representados enquanto realizam a mesma atividade física, ou uma figura feminina histórica famosa apresentada aos /às jovens leitores/as.

Na mesma época na Itália, em 1986 é publicada outra importante obra Il sessismo nella lingua italiana, organizada por Alma Sabbatini (1986), que trazia Recomendações para o uso não sexista da língua italiana. O estudo de Sabatini também revelou a preocupação com a análise da linguagem sexista e consistiu em uma outra importante contribuição para a igualdade de gênero italiana. Ao propor a análise da linguagem sexista, Alma Sabatini tinha como dos principais propósitos problematizar os preconceito linguísticos contra as mulheres, estimulando e favorecendo uma mudança no modo de pensar, de agir e de expressar. Afinal a língua que se usa quotidianamente é um dos meios mais pervasivo/penetrante e menos identificado de transmissão de uma visão de mundo na qual encontra amplo espaço para as hierarquias de gênero, para o princípio de inferioridade e marginalidade social da mulher. Esta importante publicação que destina a indicação de propostas e alternativas, não prescritivas, mas que oferecem estímulos à reflexão, com sugestões abertas e problematizadoras, para quem faz o uso da língua, e usando-a e exercitando-a como uma ação política. 
A obra apresentava os principais aspectos do sexismo lingǘstico e revelava como o universo lingüístico está organizado em torno do homem, enquanto a mulher continua ser apresentada com uma imagem estereotipada e menosprezada, e que não corresponde mais a realidade em que vivemos. Trinta anos depois da publicação da obra de Sabatini, o trabalho ainda mostra validade total em questões e questões que investem as esferas linguística, cultural, social e política. As grandes mudanças destes últimos anos em nossa sociedade não são ainda espelhadas na língua, tal contexto trazem para os estudos de gênero grandes desafios de pesquisa.

\section{Educação para a emancipação de gênero na Itália}

Um processo de educação crítica dos elementos presentes na socialização de gênero, das mensagens rotulantes. Através da exposição diária de exemplos estereotipados, compartilhados, sancionados publicamente, sinalizando lugares e papéis sociais. Neste sentido a definição de "educazione di genere" refere-se a planos de trabalho com as famílias, escolas, instituições do sistema de formação integrada. Este é uma característica central, quando analisamos o processo de Educação para promoção da Igualdade de gênero, no contexto italiano. Com educação de gênero se entende como um "conjunto de ações, com atenção cotidiano, de modo intencionalmente, por aqueles que têm a responsabilidade pela educação (pais, mães, professores, professoras etc.) sobre as experiências relacionadas aos papéis de gênero e relações de gênero das crianças e dos jovens" (Leonelli, 2011, p.03).

O contexto das políticas públicas italiana da educação para a emancipação de gênero, em um sentido amplo, reconhece que, grupos culturais, sociais, políticos, participam da educação de gênero, e que influenciam sobre o tema. Assim as propostas educativas e as ações intencionais para atingir este objetivo, não estão somente na dimensão educacional, restrita à competência meramente das instituições escolares. Mas sim extrapolam o muro da escola e compartilham um projeto social, político e cultural com toda a sociedade (destacamos o envolvimento com Editoras, Festival de arte, envolvendo Casas de Cultura, teatro, Comunidade e também as famílias).

Com os dados desta pesquisa, foi possível perceber que a construção de um projeto para a igualdade de gênero italiana, tem como base um significado cultural, bem como política, que muda toda a perspectiva de intervenção. A igualdade de oportunidades não são mais vistos como um mundo à parte, ou como um problema a ser resolvido separadamente, mas como uma questão a ter em mente em qualquer iniciativa política ou qualquer outra atividade, resultando em ações e projetos que não negligenciam a luta contra a discriminação, a tomar as ações positivas que dão valor e visibilidade aos caminhos, culturas e habilidades de homens e mulheres, meninos e meninas.

A descrição da Pedagogia de gênero, de acordo com Leonelli (2011), se ocupa dos seguintes aspectos: detectar os modelos implícitos de meninos e meninas que são referenciados diariamente por professores/as, educadores/as, famílias; Observar como esses padrões são traduzidas na prática por meio de regras, reforços, punições, etc. Comparar a educação de gênero contemporânea com exemplos de 
educação tradicional e as mais recentes transformações de gênero, tanto sobre as questões teóricas, quanto aquelas ligadas a novas atitudes sociais; Estudar as propostas de educação comumente praticada atualmente, e as propostas praticadas em diferentes lugares do mundo, identificando trajetórias, objetivos, etc., a fim de verificar convergências e distanciamentos. Finalmente, a Pedagogia de gênero tem uma atitude pró-ativa de contínuo reconhecimento dos constrangimentos de gênero, ou seja, aqueles constrangimentos que oferecem uma imagem estereotipada de meninas e meninos, imagens degradante para as mulheres e irrealistas para o sexo masculino, e que serve para promover uma reflexão capaz de compreender novas questões que estão presentes nas escolas, nos processos educativos com as crianças.

Na Itália a Pedagogia de gênero já tem sua própria história, na qual é possível identificar três etapas de consolidação da atenção para a dimensão de gênero nos contextos educacionais, para eliminação dos preconceitos sexistas. No que se trata da elaboração de documentos orientadores para a eliminação dos estereótipos de gênero, destacamos o Projeto Polite - Pari Opportunità e Libri di Testo. O Projeto Polite iniciou após a discussão e publicação da Plataforma de Pequim que, em 1985, identificou 12 áreas críticas para intervir no sentido de promover Igualdade de Oportunidades: entre elas estava a educação e formação profissional das mulheres. Em particular, a ONU informou pela primeira vez que os currículos escolares e os materiais didáticos eram sexistas e estereotipados, denunciando que esses aspectos favoreciam o fortalecimento dos papéis tradicionais de homens e mulheres. As ações específicas para a igualdade de oportunidades também foram incluídas na atualização de materiais didáticos e a construção de uma cultura de diferença de gênero. A partir desta chamada, de estudos realizados, e também das outras orientações internacionais em relação à temática da discriminação de gênero, na Europa se havia chegado à elaboração do Projeto Polite, que busca enfrentar o problema das discriminações de gênero nos textos escolares:

Polite é um projeto europeu de autorregulamentação para a editoria escolar, nascido com o objetivo de promover uma reflexão cultural, didática e editorial, cujo êxito era o de repensar os livros de texto de modo tal que homens e mulheres, protagonistas da cultura, da história, da política e da ciência fossem presentes nos livros de texto sem discriminação de sexo. (Seveso, 2016, p. 76).

O Projeto Polite propõe publicar textos escolares com algumas características fundamentais: evitar linguagens sexistas e estereótipos sexuais; fornecer representações equilibradas das diferenças; promover a formação de uma cultura da diferença de gênero, repensar a linguagem. Modernizar e adequar a escolha das ilustrações. Verificou-se uma interessante mudança na produção editorial de textos de narrativa dirigida a meninos/as e garotos/as, porque muitas casas editoras propuseram histórias e personagens que introduzem estereótipos não tradicionais em relação ao gênero (Seveso, 2016). O Projeto Polite, e seus desdobramentos relacionados principalmente às publicações de livros diferenciados, representa um marco e um grande passo à questão da Pedagogia das diferenças de gênero, no contexto italiano.

Neste sentido, com o desafio de dar ênfase para a literatura infantil não sexistas destinada às crianças, trazemos a seguir uma análise sobre as contribuições de Astrid Lindgren, destacando algumas dimensões presentes em suas obras, para problematizar as marcas de gênero nos livros para crianças. 
Revelando que a literatura para a infância, que parece ser uma tipologia de importância secundária, ao contrário, pode desenvolver transformações nas vidas de meninos e meninas.

\section{Os modelos de ruptura radical dos livros de Astrid Lindgren}

Os livros pioneiros de Astrid Lindgren destinados às crianças se mostram como importantes referências sobre a temática, livros que influenciaram a literatura italiana e estrangeira. Seveso (2015) aponta que a leitura das obras de Astrid Lindgren permitem lidar com uma multiplicidade de temas extremamente fascinantes, representados pelas personagens protagonistas de livros as heroinas lindgreniani, trazendo uma discussão interessante e significativa sobre os estereótipos de gênero. A mais famosa das heroínas lindgreniani, a personagem Pippi Meiaslongas (Tradução publicada na Itália como Pippi Calzelunghe, em 1958) é de fato, um modelo de ruptura radical, inovador para o seu tempo, inverte narrativa clichê de costume, que representavam as meninas e as mulheres mais jovens como dócil, obediente, gentil, elegante e sóbria, educada, comportada e virtuosa, um modelo feminino estereotipado (Seveso, 2015).

A escandalosa Pippi, a irredutível moleca, a irreverente, irônica e contestadora Pippi, é sempre atual. Depois de haver assinalado um decisivo divisor de águas na história da representação das meninas, a quem ofereceu novas e libertárias fantasias das quais se alimentar, Pippi permanece um exemplo a ser seguido para explorar recursos desconhecidos, para contagiar os leitores com sua força vital e pela sátira que dirige ao sistema de proibições do mundo adulto.

Pippi parece ser a resposta feminina a tantos livros que narram histórias de moleques. Todos do sexo masculino. E nasce da pena inspirada e inventiva de Astrid como um tipo de alteridade ingovernável ou de alter ego: “(...) não sou eu quem decide como devem ser minhas meninas. Elas fazem como querem, e sou eu quem devo me adaptar (...)" e, ainda, "muitas meninas dos anos 40 me escrevem, depois, já adultas, para me contar sobre o sentimento de libertação que experimentaram ao ler Pippi, e o quanto era importante que fosse uma menina (...)". As mulheres fortes, sábias e corajosas da infância de Astrid retornam como modelo positivo a se atingir, para renovar mensagens de liberdade. (Beseghi, 2012, p.143).

A originalidade e efervescência da trama, as desconcertantes invenções narrativas, a fonte inesgotável de criatividade, a incontrolável espontaneidade da personagem. "A aventura em Pippi é aquela de tantas meninas decididas a não abdicar de sua coragem ou de sua força inventiva, meninas intrépidas, prontas a desafiar as convenções, a desmascarar os preconceitos e os lugares-comuns" (Beseghi, 2012, p.139). Distanciar deste modelo tradicional, segundo Seveso (2015) no livros de Astrid Lindgren, não simplesmente propor a derrubada do estereótipo feminino tradicional, mas as heroínas lindgreniani, na verdade, constituem um modelo em si, com características próprias, complexas e multifacetadas, envolvem um conjunto de características femininas que não são a mera inversão do estereótipo tradicional, nem mesmo uma espécie de cópia das características masculinas, mas sim possuem especificidade de personagens femininas, com os seus próprios poderes, suas forças próprias, seus próprios carismas, e com uma carga revolucionária. 
Seveso (2015) destaca dois aspectos que nos ajudam a compreender e analisar a especificidade do feminino nas heroínas lindigreniani, (e que podemos mais adiante relacionar com outros livros analisados): os espaços ocupados pelas meninas e a dimensão da corporeidade. A questão dos espaços certamente representam um modelo inovador, este aspecto é talvez o que mais se afasta modelos tradicionais. Distancia-se de outros autores que sempre colocam as meninas dentro de espaços confinados, muitas vezes limitada espaços domésticos, longe do inesperado e do desconhecido, modo este de representação que reflete nas práticas educativas em geral, para as meninas. Este é motivo pelo qual, Beseghi (2008) aponta, porque as meninas foram excluídas de um gênero literário tão rico a partir de um ponto de vista simbólico, que é a aventura.

A viagem, a liberdade para explorar, experimentar, conhecer lugares e saberes novos, ou seja a aventura está configurada para as meninas como o lugar interditado. A dimensão dos espaços abertos e da aventura está presente nos livros de Astrid Lindgren, com a exploração de lugares e situações desconhecidas, buscando soluções criativas e prática diante de uma situação imprevisíveis. Pippi representa assim uma menina aventureira, entre o real e o simbólico. Salienta que, mesmo no que respeita à dimensão do espaço e aventura, não representa um modelo único, ou um modelo que constitui a simples derrubada do tradicional: as meninas movem-se livremente nos espaços abertos e corajosamente enfrentam a aventura, mas também ocupam os espaços aconchegantes de afeto da escritora como a cozinha.

A dimensão da corporeidade, segundo Seveso (2015) sempre constituiu como problemático e complexo para as meninas, tanto nas práticas educativas, tanto dentro da literatura infantil: o modelo tradicional responde a um ideal do mundo adulto que quer a menina comportada, tranquila frágil, com gestos controlados e o mais comedido possível. Nos livros de Astrid Lindgren, este estereótipo também é problematizado, coexistindo com modelos múltiplos. Uma característica que se destaca é extraordinária força de Pippi, que exibe uma gama de gestos extravagantes, como poder carregar sustentar seu cavalo, mais uma vez misturando elementos entre o fantástico, o transgressivo.

A personagem clássica e pioneira Pippi Meias Longas, nos dá pistas para analisar outras personagens dos livros para crianças. Pippi foi também um modelo que que permitiu fornecer para as crianças armas para defenderem da arrogância e incompreensão dos adultos. Através Pippi as meninas poderiam sonhar em se tornarem fortes e independentes, e aspiram a ser grande, e jogarem fora tudo aquilo que poderia ser um obstáculo à liberdade de ser, de agir, de pensar. (Ziliotto, 2008).

\section{Mudanças nos livros de literatura infantil com as temáticas anti-sexistas}

Elena Gianini Belotti, realizou estudos pioneiros sobre a literatura destinada às crianças, onde apontou que são transmitidos os valores culturais da sociedade em que vivemos, com indicações precisas de como se vive ou se deveria ou se desejaria que se vivesse, do que é bom e do que é mau, do que é belo e do que é feio, do que é desejável e do que é indesejável. (Gianini Belotti, 1978). 
Com as pesquisas de Belotti, Rossana Pace e Alba Sabatini, foi possível identificar uma significativa mudança na Itália na publicação de livros de narrativa e de ficção para meninas e meninos: nos anos setenta e oitenta, as editoras italianas estavam bem fundamentadas nesta questão. Rossellina Archinto, por exemplo, fundou as Edições Emme e dedicou-se às primeiras ilustrações, começando com Little Blue e Little Yellow ${ }^{4}$ (1967), com uma particular sensibilidade para os temas das diferenças e com foco em apresentar os artistas da Itália como Lionni, Sendak, Mari e outros. Esta editora naqueles anos ofereceu livros inovadores, tanto do ponto de vista de gráficos, cores, design, dando a mesma relevância para as ilustrações e o texto. A colaboração com o renomado arquiteto e artista Bruno Munari também abriu o caminho para novas experiências relacionadas ao objeto do livro, destacando a importância de envolver as crianças através da manipulação e do jogo.

Outra mudança significativa foi feita por Donatella Ziliotto, escritora, tradutora e editora, que, declarando-se explicitamente por parte de crianças, propôs através de seus livros uma visão alternativa de um mundo adulto caracterizado por regras e constrangimentos. A intenção era fazer os leitores entenderem que é possível imaginar um futuro diferente do que os pais e a sociedade exigem. Esses temas foram abordados nas duas coleções que ela criou: The Fisherman Martin ${ }^{5}$ para a editora Vallecchi e Gl'istrici para Salaní. Donatella Ziliotto também tem a revolucionária tradução para o Italiano e publicação das aventuras de Pippi Calzelunghe.

Nos anos setenta, Adela Turim e a Bósnia fundaram outra editora com um nome já significativo, From the Girls 'Party': o objetivo era derrubar a imagem estereotipada de feminino como inferior, dócil, privada, propondo modelos femininos não convencionais e fantásticas histórias não estereotipadas, como aquelas na seção dedicada a Rosaconfetto ${ }^{8}$ e outras histórias.

Assim, buscou-se discutir a partir das mensagens dos livros direcionadas à meninas e aos meninos, os significados atribuídos a mulheres e homens, ao feminino e ao masculino, a presença das questões de gênero, com a intenção de problematizar como a literatura transmite valores sobre os papéis sociais de homens e mulheres. Com a ótica dos estudos de gênero, buscou identificar o processo de desconstrução dos estereótipos de gênero, e também visualizar as possibilidades de rompimento das dicotomias feminino versus masculino. Ao fazer a análise, é possível afirmar que discutir a educação de meninas e meninos, a partir daquilo que se oferece e disponibiliza intencionalmente para elas/eles é uma questão que envolve gênero e poder (Vianna e Finco, 2009).

\footnotetext{
4 "Piccolo blue piccolo giallo" é um livro clássico para crianças, sobre o tema do encontro com o outro, da diversidade, da identidade, escrito e ilustrado por Leo Lionni.

5 The Fisherman Martin foi uma coleção de livros infantis considerada "pioneira" que renovou a paisagem literária na Itália através da introdução de muitas traduções do exterior, incluindo as obras de Astrid Lindgren, Tove Jansson, Michael Ende. Infelizmente, após sete anos de atividade, a série foi fechada devido a dificuldades econômicas de Vallecchi.

6 Gli Istrici uma coleção fundada por Donatella Ziliotto quando The Fisherman Martin foi fechada. GI'Istrici (Editora Salani) também buscou publicar muitos autores estrangeiros na ltália e ainda hoje publica textos narrativos interessantes para crianças. Salani é uma das mais antigas editoras italianas e desde o ínicio já era sensível ao tema da literatura para infância.

7 Esta pequena editora, durante os anos setenta e oitenta, publicou muitos textos relacionados ao tema da diferença de gênero, com atenção tanto para as histórias quanto para os aspectos textuais quanto das imagens.

8 Rosaconfetto foi uma série bem sucedida dos anos setenta, que apresentava de forma concreta e inteligente o problema do sexismo.
} 
Desse modo, é possível analisar as mensagens de gênero presente nos livros infantis, problematizando aquelas mensagens voltadas para a normalização e o controle das expectativas relacionadas aos papéis sociais desempenhados por meninas e meninos, mulheres e homens, destacando também aquelas que revelam as transformações e possibilidades de mudanças frente aos estereótipos de gênero, registradas nos livros para crianças.

As modernas sociedades ocidentais fixaram as características "básicas" da masculinidade e da feminilidade a partir dos aspectos biológicos. A normalização da dicotomia homens versus mulheres acabou por fundar a forma de pensamento segundo a qual há um jeito de ser feminino e um jeito de ser masculino: há comportamentos, falas, gestos, posturas físicas, além de atividades e funções que são entendidas como adequadas, "naturais" e apropriadas para as mulheres ou para os homens, sendo características percebidas como uma extensão da "natureza" de cada sexo. Quando observamos os livros destinados às crianças, alguns clássicos permanecem até hoje no repertório de histórias infantis como os de Perrault e os dos irmãos Grimm. Essas primeiras obras tinham não tinham um fim educativo, eram obras que retratavam situações da época enfrentadas pelos adultos (Botton e Strey, 2011).

Analisando sob a perspectiva das mensagens ligadas a corporeidade, a cultura exacerbada do corde-rosa para as meninas, a centralidade e obrigatoriedade de um padrão de beleza, a preparação para o casamento (espera do príncipe encantado), e o confinamento no espaço domésticos são questões abordadas nos livros destacados que ajudam as crianças a pensar criticamente, levam a conhecer outros modelos e possibilidades de escolha das meninas. A princesa que está sempre suja e despenteada, a princesa que gosta de leitura, a princesa que não queria vestidos, que estava cansada do cor-de-rosa e dos sapatos de saltos, afinal existem muitas outras possibilidade de ser princesa, de feminina e de ser mulher. Sob a perspectiva dos espaços ocupados pelas meninas/mulheres, destacamos os enredos das histórias nas quais o confinamento no espaço doméstico, se contrapõe ao direito à mobilidade, direito à frequentar espaços públicos, ou mesmo o direito à aventuras, de voar de balão, de caçar dragões, de ser uma princesa-pirata e conquistar o mar...

Segundo a pesquisa de Wilke (2008) durante anos as crianças ouvem histórias semelhantes. "E, tendo-se em vista o longo caminho se submissão da mulher, observamos que pouco se avança, quando o modelo é contado e recontado por meios de artifícios simbólicos, que capturam a criança sem o desenvolvimento de sua crítica" (p.30). Assim, destacamos por exemplo, a potencialidade dos recontos dos clássicos e podemos identificar como estes livros problematizam e ajudam a criticar os estereótipos de gênero e os lugares assumidos pelas mulheres e homens nos contos clássicos, conhecidas pelas crianças. "Biancaneve $i 77$ nani" que faz uma crítica ao papel feminino da personagem, principalmente com a problematização do trabalho doméstico. "Signorina Si-slavi-chi-può" que conta uma outra versão da Chapeuzinho vermelho e revela uma menina, personagem destemida que afronta o lobo. "Principessa salvata di libri" desconstrói o enredo da Rapunzel, problematizando a ideia da preocupação com a beleza, da espera do príncipe encantado e do casamento e traz a temática da leitura como um prazer para a meninamulher. 
Podemos reconhecer a literatura infantil não sexista como ferramenta privilegiada para discutir com as crianças as transformações nos valores da nossa sociedade atualmente. Os saberes presentes neste materiais podem integrar o currículo na educação infantil, na construção de um projeto que eduque meninas e meninos, construindo uma educação para a igualdade de oportunidades, contra as violências de gênero, que ofereçam às crianças modelos mais expressivos, mais livres dos estereótipos. O sexismo e todas outras formas de preconceitos acontecem nas vivências das crianças, desde idade muito precoce, desse modo estas questões devem ser abordadas e discutidas para que haja transformação.

A ideia de olhar para os livros e literaturas infantis busca desconstruir estereótipos e normatizações de comportamentos entre homens/meninos e mulheres/meninas e visa provocar deslocamentos de sentidos, transformações e criações de novas narrativas com possibilidades nas entrelinhas das histórias de evidenciar conceitos feministas: de sororidade, empoderamento feminino, princípios políticos emergentes à uma pedagogia descolonizadora emancipadora, no cotidiano de creches e pré-escolas e também em cursos de formação inicial e continuada. (Finco e Silva, 2016).

Destacamos que o desafio do combate e da eliminação dos estereótipos e das violências de gênero no âmbito da educação, está ligado diretamente a formação docente e aos suportes nas legislações. Nos dias atuais, a temática da diferença de gênero na Itália aparece no último texto da Lei relativa à Escola (Lei 107/2015, conhecida como "Buona Scuola") e, em particular, no documento do Ministério de formação de professores. Depois de muitos anos, finalmente, o Ministério Italiano enfrenta com clareza a questão de gênero na formação docente, com foco na intervenção, através da criação de um sistema real e próprio de formação. Neste documento, a escola é definida como um elemento ativo, capaz de promover e incentivar uma comunidade atenta aos direitos, deveres, responsabilidades, liberdade. $\mathrm{O}$ documento diz respeito à educação para o respeito dos outros; o reconhecimento do valor da diversidade como um recurso de ensino e não como uma fonte de desigualdade; a luta contra a discriminação; a prevenção do bullying e do cyberbullying; a potencialização dos conhecimentos básicos e habilidades para a vida... e indica, entre as estratégias, a "capacidade de apoiar o desenvolvimento de uma cultura de igualdade de oportunidades e respeito pelos outros". O documento traz também outra questão importante para tratar as questões de gênero que diz respeito à "Intercultura", destacando tal conceito como chave para favorecer a igualdade de oportunidades, para promover a idéia moderna de cidadania consciente.

\section{Considerações Finais}

A construção da Pedagogia das diferenças de gênero passa por um importante processo de formação docente. Educar para a diferença de gênero significa introduzir no cotidiano educativo das meninas e meninos, elementos conceituais anti-sexistas e experiências inovadoras para suas vidas.

$\mathrm{Na}$ história da pedagogia houve uma descoberta tardia das relações de gênero que permeiam os processos educativos das crianças, bem como os processos de formação de professoras/es. Porém é possível destacar o rompimento do silêncio da área com os estudos de gênero, apontando para os desafios 
e contradições contemporâneas de uma pedagogia das diferenças comprometida com a emancipação humana.

Nesta direção, uma das chaves deste processo pode ser a construção de poéticas da resistência articulando pedagogia, formação docente a partir de uma experiência literária não sexista. Apontamos que os livros de literatura infantil, podem ser uma ferramenta estratégica para sensibilizar em relação ao estereótipo de gênero e para a difusão de uma cultura de gênero na formação docente e na prática pedagógica. O contexto da formação docente pode oferecer pistas para repensar criticamente os programas educativos e o desenvolvimento de uma maior consciência sobre a discriminação de gênero.

\section{Referências}

ARGÜELLO, Zandra Elisa. Dialogando com crianças sobre gênero através das literaturas infantil. Porto Alegre: UFRGS, 2005. Dissertação (Mestrado em Educação), Faculdade de Educação, Universidade Federal do Rio Grande do Sul, 2005.

BESEGHI, Emy. Ombre rosa. Le bambini tra libri, fumeti e altri media. Giunti e Lisciani Editori, Teramo, 1987.

BESEGHI, Emy. Piccole donne crescono. L'editoria per l'infanzia dalle bambine alle adolescenti, in BESEGHI, Emy., TELMON, V. (Orgs.), Educazione al femminile: dalla parità alla differenza, La Nuova Italia, Firenze, 1992, pp. 135-151.

BESEGHI, Emy. Infanzia e racconto, Bononia University Press, Bologna 2008.

BESEGHI, Emy. Verso nuovi percorsi ermeneutici. Immaginario, letteratura per l'infanzia, storia dell'educazione. Rivista di Storia dell'educazione, anno 3, 2016, numero 2, 45-56.

BESEGHI, Emy. No centenário de Astrid Lindgren: a gaveta secreta de Píppi Meialonga. Cad. CEDES, vol.32, n.86, 139-143, 2012.

BIEMMI, Irene. Educazione sessista. Stereotipi di genere nei libri delle elementari, Rosenberg \& Sellier, Torino 2010a.

BIEMMI, Irene. Genere e processi formativi. Sguardi maschili e femminili sulla professione di insegnante, ETS, Pisa, 2010b.

BIEMMI, Irene. The imagery of gender in Italian textbooks. Research into primary school books. Foro de Educación, 13(18), 2015, 15-35. 
BOTTON, Andressa e STREY, Marlene Neves. A influência do Gênero na Infância: como produzimos meninos ou meninas. In: STREY, Marlene Neves; BOTTON, Andressa; CANODÁ, Eliane e PALMA, Yáskara Arrial (Orgs.) Gênero e ciclos vitais: desafios, problematizações e perspectivas. EDIPUCRS, 2011, pp.23-42.

DE CAROLI Maria Elvira, SAGONE Elisabetta. Un puzzle di genere, un genere di puzzle. Prospettive teoriche e studi empirici sugli stereotipi in età evolutiva, Roma, Bonanno Editore, 2010.

DE CONCILIS, Eleonora. La riproduzione (del) femminile. Una riflessione socio-politica sul ruolo delle donne nella scuola italiana degli ultimi decenni. Storia delle donne, 8(2012), 356-391.

FARIA, Ana Lúcia Goulart de Faria. Pequena infância, educação e gênero: subsídios para um estado da arte. Cad. Pagu. 2006, n.26, 279-287.

FINCO, Daniela; SOUZA, Adalbeto. S.; CRUZ, Nara R. (Org.). Educação e Resistência Escolar: gênero e diversidade na formação docente. São Paulo: Editora Alameda, 2017.

FINCO, Daniela; SILVA, Adriana. Cinema, transgressão e gênero: as infâncias de Baktay e Wadjda. Dossiê Gênero, Mídia e Infância. Perspectiva (UFSC), v. 33, 2015, 933-960.

GIANINI BELOTTI, Elena. Dalla parte delle bambine, Feltrinelli, Milano,1978.

LEONELLI, Silvia. La pedagogia di genere in Italia: Dall'uguaglianza alla complessificazione. Ricerche di Pedagogia e Didattica, Bologna, 2011, pp.1-6.

PACE, Rossana. Immagini maschili e femminili nei testi per le elementari. Roma: Presidenza del Consiglio dei Ministri, 1986a.

PACE, Rossana. Commissione Nazionale per la realizzazione della parità tra uomo e donna, Immagini maschili e femminili nei testi per le elementari.Roma, Presidenza del Consiglio dei Ministri, Direzione generale delle informazioni dell'editoria e della proprietà letteraria artistica e scientifica, 1986b.

PELLERINO, Mariagrazia. Presentazione. Genere, educazione e processi formativi. in VENERA, Anna Maria (Orgs.). Genere, educazione e processi formativi: riflessioni teoriche e tracce operative, Edizione Junior, Parma, 2014, pp.76-89.

ROMATOWSKI, J. A., TREPANIER-STREET, M. L., The influence of children's literature on gender role perceptions: a reexamination, Early Childhood Education Journal, 1999, 26(3): 155-159.

SABATINI, Alma. Il sessismo nella lingua italiana, Roma, 1993. 
SEVESO, Gabriella. Astrid Lindgren e le eroine al di là degli stereotipi di genere. in.: B. De Serio (Orgs.), Scrittrici d'infanzia. Dai libri per bambini ai romanzi per giovinette, Progedit Editore, Bari, 2015, pp. $145-161$.

SEVESO, Gabriella. Fumette. Valentina, Eva Kant, Lara Croft e le altre, Edizioni Unicopli, Milano 2000.

SEVESO, Gabriella. Come ombre leggere. Gesti, spazi, silenzi nella storia dell'educazione delle bambine, Edizioni Unicopli, Milano 2001.

SEVESO, Gabriella. Diferenças de gênero e livros para a infância: reflexões sobre os estereótipos de gênero nos livros escolares italianos. Revista Crítica Educativa (Sorocaba/SP), v. 2, n. 2, dez.2016, 107122.

SALGADO, Raquel Gonçalves. Da menina meiga à heroína superpoderosa: infância, gênero e poder nas cenas da ficção e da vida. Cad. CEDES. 2012, vol.32, n.86, 117-136.

ULIVIERI, Simonetta. Educare al femminile, ETS, Pisa 1995. Ulivieri Simonetta. (Orgs.), Educazione al femminile. Una storia da scoprire, Guerini e Associati, Milano 2007.

VENERA, Anna Maria (Orgs.). Genere, educazione e processi formativi: riflessioni teoriche e tracce operative, Edizione Junior, Parma, 2014.

VIANNA, Cláudia e FINCO, Daniela. Meninas e meninos na Educação Infantil: uma questão de gênero e poder. Cad. Pagu. 2009, n.33, 265-283.

ZILIOTTO, Donatella, La rivolta del bambino di plastica. Libri e collane per insegnare ai bambini a difendersi dai genitori, in BLEZZA PICHERLE, Silvia (Orgs.), Rileggendo Astrid Lindgren. Percorsi critici e itinerari interpretativi, Edizioni del Cerro, Tirrenia 2008, pp. 167-181.

WILKE, Maria Elisa V. M. A transmissão dos modelos femininos e masculinos nos livros infantis. In: STREY, M. N.; WILKE, Maria Elisa V. M.; RODRIGUES, Roberta de Alencar.; BALESTRIN, Viviane G. (Orgs). Encenando Gênero: cultura, arte e comunicação. Porto Alegre: EDIPUCRS, 2008. pp. 223251. 